\title{
Health seeking behavioral analysis associated with breast cancer screening among Asian American women
}

This article was published in the following Dove Press journal:

International Journal of Women's Health

15 May 2012

Number of times this article has been viewed

\author{
Grace X Ma' \\ Wanzhen Gao' \\ Sunmin Lee ${ }^{2}$ \\ MinQi Wang ${ }^{3}$ \\ Yin Tan' \\ Steven E Shive ${ }^{1,4}$ \\ 'Department of Public Health, Center \\ for Asian Health, College of Health \\ Professions, Temple University, \\ Philadelphia, PA, USA; ${ }^{2}$ Department \\ of Epidemiology and Biostatistics, \\ School of Public Health, University \\ of Maryland, College Park, MD, \\ USA; ${ }^{3}$ Department of Public and \\ Community Health, University of \\ Maryland, College Park, Maryland, MD, \\ USA; ${ }^{4}$ East Stroudsburg University, \\ East Stroudsburg, PA, USA
}

Objective: The purpose of this community-based study was to apply a Sociocultural Health Behavior Model to determine the association of factors proposed in the model with breast cancer screening behaviors among Asian American women.

Methods: A cross-sectional design included a sample of 682 Chinese, Korean, and Vietnamese women aged 40 years and older. The frequency distribution analysis and Chi-square analysis were used for the initial screening of the following variables: sociodemographic, cultural, enabling, environmental, and social support. Univariate and multivariate analyses were conducted on factors for breast cancer screening using multinomial logistic regression analysis.

Results: Correlates to positive breast cancer screening included demographics (ethnicity), cultural factors (living in the United States for 15 years or more, speaking English well), enabling factors (having a regular physician to visit, health insurance covering the screening), and family/ social support factors (those who had a family/friend receiving a mammogram)

Conclusions: The results of this study suggest that breast cancer screening programs will be more effective if they include the cultural and health beliefs, enabling, and social support factors associated with breast cancer screening. The use of community organizations may play a role in helping to increase breast cancer screening rates among Asian American women.

Keywords: breast cancer screening, Vietnamese, Korean, Chinese, breast cancer, Asian American

\section{Introduction}

Cancer is the number one cause of death among Asian American women ${ }^{1}$ and Asian American women have the lowest cancer screening rates of all ethnic groups in the United States. ${ }^{2}$ The American Cancer Society ${ }^{3}$ reports a breast cancer incidence rate of 81.6/100,000 and a mortality rate of $12.5 \%$ among Asian American women. Breast cancer is the leading cancer among Chinese, Korean, Vietnamese, and Cambodian American women. ${ }^{4}$ Epidemiological studies have indicated an increase in breast cancer risk among Asian women and their descendants following immigration to the United States. ${ }^{5,6}$

Early detection plays an essential role in reducing breast cancer morbidity and mortality. It is recommended by the American Cancer Society, the Michigan Cancer Consortium, and the American Medical Association that women aged 40 years and older have mammograms annually. Despite the effectiveness of early detection in reducing breast cancer mortality, rates of these preventive health practices remain low among many minority women. ${ }^{7}$ Mammogram screening rates are lower among Asian American women; only 57\% had a mammogram within the previous 2 years 
and only $48 \%$ within the previous 12 months, compared with $72 \%$ and $57 \%$ (respectively) among white women in the United States. ${ }^{8}$ Furthermore, Asian and Pacific Island women, for example, have been diagnosed at a much later stage of breast cancer, largely due to lack of timely screening and early detection. ${ }^{9-11}$

There are differences in cancer screening among Asian American subgroups..$^{2,12-14} \mathrm{Ma}$ et $\mathrm{al}^{13}$ reported that never-screened rates for mammography ranged from $20 \%$ in Chinese, to $28 \%$ in Vietnamese, $30 \%$ in Korean, and $79 \%$ in Cambodian women residing in the mid-Atlantic area; and the 12 -month screening rates were $58 \%, 38 \%, 42 \%$, and $11 \%$, respectively. Studies focusing on individual Asian ethnic groups showed some variations. Among Chinese American women, the rate of having ever undergone mammogram screening ranged from $71.1 \%{ }^{7}$ to $74.0 \%{ }^{15}$, and $43 \%$ of women reported screening in the last year. ${ }^{7}$ Among Korean American women, screening rates have ranged from $55 \%$ to $78 \%$ among those aged $\geq 50$ years, ${ }^{16}$ with $38.6 \%$ of these women having had one within the previous year. ${ }^{17}$ Among southeast Asian women, about $70 \%$ of women aged 40 years and older ever had a mammogram, with 56\% having had one in the last 2 years. ${ }^{18}$ Among Vietnamese women, $45 \%$ received a mammogram and $15 \%$ within the last year. ${ }^{19}$ Among Vietnamese women aged 40 years and older, 26\% had a mammogram. ${ }^{20}$

Various reasons have been cited for underutilization of screening, including language difficulty, cultural and acculturation factors, economic barriers, and a lack of health insurance coverage. . $, 8,13,14,21,22$ Women who had health insurance and a usual source of care, and who had seen a physician in the past year, were more likely to have been screened. ${ }^{14}$

\section{Conceptual model}

$\mathrm{Ma}^{23}$ developed a Sociocultural Health Behavior Model by incorporating the major constructs of the health belief model, ${ }^{24}$ social cognitive theory, ${ }^{25,26}$ the behavioral model, and access to medical care. ${ }^{27}$ The Sociocultural Health Behavior Model acknowledges that the complexity and interaction of multiple factors play a major role in many patients' health-seeking behaviors. It explains health-seeking behavior by describing the relationships among individual, interpersonal, and environmental factors. This model describes relationships between individual health behavior and interaction with the environment. The interactions and multiple levels of influence of individual, interpersonal, and environmental factors underlying health behavior are emphasized.
Since screening behavior is influenced by multiple factors, there is a need to identify the associations among these factors. The role of cultural factors is seldom included in a health behavior analysis. In addition to common theoretical components, this model includes cultural factors as a primary component. The model incorporates the interdependence of predisposing, enabling, need, family/social support, environmental health system, and cultural factors, all of which contribute to a particular health behavior or outcome. A number of variables can be included under cultural factors; these include notions of fatalism, birth in the United States, years lived in the United States, English fluency, use of native language at home, native food dietary habits, use of media sources in the native language, and attendance at native-themed social events.

The purpose of this community-based study was to apply the Sociocultural Health Behavior Model to determine the association of factors proposed in the model with breast cancer screening behaviors among Asian American women.

\section{Methods}

\section{Sample}

The current study was part of a larger screening study of Chinese, Korean, Vietnamese, and Cambodian Asian Americans. To obtain a representative sample, a current listing of 111 Asian American community organizations in the greater Philadelphia area, New Jersey, and New York City was identified by the Asian Community Health Coalition and Center for Asian Health, Temple University (Philadelphia, PA). The 111 community organizations were located in geographic areas which maximized the coverage of Asian Americans across ethnic groups, age, and socioeconomic status. Asian American community organizations $(\mathrm{N}=52)$ were randomly selected as clusters from the list of 111 organizations. A proportional sampling procedure was adopted based on the size of the four ethnic groups, with the size of the Chinese group twice the size of the Korean and Vietnamese groups. ${ }^{28}$ The 2098 participants were recruited from the 52 Asian American community organizations. Among those recruited, 2011 participants completed the survey (a response rate of $95.9 \%$ ).

For the purpose of this paper, only Asian American women (Chinese, Korean, and Vietnamese), aged 40 years or older were retained for the analysis; the final sample comprised 724 participants. Of these, 440 (60.77\%) were Chinese, 139 (19.20\%) were Koreans, and 145 (20.03\%) were Vietnamese. 


\section{Design and data collection procedures}

A cross-sectional research design was used in the study because of the common advantages provided by this method, such as collecting information from numerous, diversified participants in a short time. Data collection and administration training were provided to all study administrators as well as to on-site bilingual translators. The research team at the Center for Asian Health, Temple University, in conjunction with organization leaders, administered the study to Asian American participants on site in the community organizations' facilities. The study was administered by using face-to-face instruction methods. Participants had the choice of responding to the questions in English or in their native language (Chinese, Korean, or Vietnamese).

\section{Measures}

A multi-lingual, 95-item questionnaire was developed, backtranslated, and pilot-tested for reliability, validity, and cultural appropriateness. It comprised of six sections: (1) demographics (age, gender, foreign born, ethnicity, marital status, education level, employment status, income, and health insurance) and acculturation (English language competency and native foods); (2) mammogram screening behavior for breast cancer; (3) perceived barriers; (4) health perceptions, based on the health belief model (susceptibility, severity, benefits, barriers, cues to action, and self-efficacy); (5) access to healthcare (physician visits and language-concordant physician); and (6) satisfaction with access to health care. The detailed information about the data collection and measures were described elsewhere. ${ }^{13}$

The original study questionnaire items were examined and selected for this study through initial screening by applying frequency distribution analysis and Chi-square analysis. The selection criteria were based on the reasonable distribution of the independent variables that met the psychometric requirements. After the preliminary screening and analysis, the following variables were retained in the analysis.

\section{The cultural factor}

Years lived in the United States, English fluency, belief that cancer is curable, self-efficacy to prevent getting cancer, fear of getting a bad test result, embarrassment/shame of being diagnosed with breast cancer, use of the Internet for information (see Table 2).

\section{The enabling factor}

Has a regular physician to visit, importance of being screened for cancers, insurance covers breast cancer screenings, communication problems, transportation problems (to the facility), lack of knowledge, and not knowing where to get services (see Table 3).

\section{The environmental factor}

Arrangements for making appointments for medical care, length of time waiting to see doctor at the office, length of time waited between making an appointment for care and the day of visit, and rating of the care of the medical group (see Table 4).

\section{The family and social support factor}

Discussion of breast cancer with significant others or family members, family/friends had a mammogram (see Table 5).

\section{The outcome variable}

The status of mammogram screening was classified into three groups: never-screened, non-compliance (not screened during the past 12 months), and compliance (screened during the past 12 months).

\section{Data analysis}

Statistical analyses included descriptive statistics (frequencies, percentages, and Chi-square statistic), and multinomial logistic regression. The multinomial logit model was used to model the $\log$ odds of outcome variable which had three levels; thus two comparisons were made between never-screened versus compliance, and between non-compliance versus compliance. Each domain (ie, cultural factors, enabling factor, environmental factor, and family and social support factor) was analyzed separately. The multinomial logit analysis was first conducted with each independent variable univariately, and then the significant variables from the univariate model were analyzed with a multivariate multinomial model. For each multinomial model, whether it was univariate or multivariate, the ethnicity variable was adjusted. All statistical analyses were conducted using statistical analysis (SAS ${ }^{\circledR}$ software, v 9.1.3, SAS Institute Inc, Cary, NC).

\section{Results}

Of 682 participants who reported their breast cancer screening status, $24.05 \%(\mathrm{n}=164)$ reported never-screened, $25.51 \%$ $(\mathrm{n}=174)$ reported non-compliance, and 50.04\% $(\mathrm{n}=344)$ reported complied. Table 1 presents the percentages and Chi-square test results for the selected demographics factors and the screening status. Of all demographic variables, only ethnicity was significantly related to the screening status, $\chi^{2}=21.32, P<0.001$. Among those who reported compliance, the majority of them were Chinese (69.39\%). 
Table I Percentages and significance test of demographic factors in relation to mammography screening status

\begin{tabular}{|c|c|c|c|c|}
\hline $\begin{array}{l}\text { Demographic } \\
\text { information }\end{array}$ & $\begin{array}{l}\text { Never screened } \\
(n=164)\end{array}$ & $\begin{array}{l}\text { Non-compliance } \\
(n=174)\end{array}$ & $\begin{array}{l}\text { Compliance } \\
(n=344)\end{array}$ & $\begin{array}{l}\text { Chi-square test } \\
P \text { value }\end{array}$ \\
\hline Age category & & & & 0.84 \\
\hline $40-64$ & 78.66 & 78.74 & 80.52 & \\
\hline $65+$ & 21.34 & 21.26 & 19.48 & \\
\hline Marital status & & & & 0.34 \\
\hline Not married & 19.50 & 25.58 & 20.82 & \\
\hline Married & 80.50 & 74.42 & 79.18 & \\
\hline Highest grade completed & & & & 0.23 \\
\hline Below high school & 28.21 & 28.57 & 28.66 & \\
\hline High school+ & 64.05 & 71.43 & 71.34 & \\
\hline Employment status & & & & 0.20 \\
\hline Employed & 55.00 & 57.89 & 63.02 & \\
\hline Unemployed & 45.00 & 42.11 & 36.98 & \\
\hline Annual household income & & & & 0.29 \\
\hline Less than $\$ 10,000$ & 41.18 & 28.99 & 35.81 & \\
\hline$\$ 10,000-\$ 30,000$ & 42.02 & 48.55 & 42.23 & \\
\hline$>\$ 30,000$ & 16.81 & 22.46 & 21.96 & \\
\hline Ethnicity & & & & 0.0003 \\
\hline Vietnamese & 23.75 & 26.01 & 14.87 & \\
\hline Korean & 24.38 & 20.81 & 15.74 & \\
\hline Chinese & 51.88 & 53.18 & 69.39 & \\
\hline
\end{tabular}

Table 2 Odds ratio and $95 \%$ confidence intervals from the multinomial analysis of cultural factor in relation to mammography screening status

\begin{tabular}{|c|c|c|c|c|}
\hline & \multicolumn{2}{|c|}{ Univariate multinomial model } & \multicolumn{2}{|c|}{ Multivariate multinomial model } \\
\hline & $\begin{array}{l}\text { Never screened vs } \\
\text { compliance }\end{array}$ & $\begin{array}{l}\text { Non-compliance vs } \\
\text { compliance }\end{array}$ & $\begin{array}{l}\text { Never screened vs } \\
\text { compliance }\end{array}$ & $\begin{array}{l}\text { Non-compliance vs } \\
\text { compliance }\end{array}$ \\
\hline \multicolumn{5}{|c|}{ Years lived in the US } \\
\hline$<15$ & $1.67(1.36,2.04)^{* *}$ & $1.08(0.89,1.3)$ & $1.65(1.29,2.12)^{* *}$ & I.I3 $(0.9, I .4 I)$ \\
\hline$>15$ & Referent & Referent & Referent & Referent \\
\hline \multicolumn{5}{|c|}{ How well speak English } \\
\hline Not at all & $1.96(1.44,2.66)^{* *}$ & $0.99(0.74,1.31)$ & $1.67(1.2,2.52)^{*}$ & I $(0.68,1.49)$ \\
\hline Not well & I.I5 $(0.87,1.53)$ & $0.87(0.68,1.12)$ & $1.02(0.73,1.44)$ & $\mathrm{I} .07(0.79, \mathrm{I} .43)$ \\
\hline Well/very well & Referent & Referent & Referent & Referent \\
\hline \multicolumn{5}{|l|}{ Cancer is curable } \\
\hline Disagree & $1.29(1.03,1.62)^{*}$ & $0.94(0.75,1.19)$ & $1.23(0.95,1.6)$ & I.II $(0.86,1.44)$ \\
\hline Agree & Referent & Referent & Referent & Referent \\
\hline \multicolumn{5}{|c|}{ There is something I can do to prevent getting cancer } \\
\hline Disagree & $1.26(0.97,1.64)$ & $1.04(0.8,1.37)$ & & \\
\hline Agree & Referent & Referent & & \\
\hline \multicolumn{5}{|c|}{ Fear of getting a bad test result } \\
\hline Yes & $1.54(1.07,2.21)^{*}$ & $1.02(0.66,1.59)$ & $1.34(0.89,2.04)$ & $1.04(0.65,1.66)$ \\
\hline No & Referent & Referent & Referent & Referent \\
\hline \multicolumn{5}{|c|}{ Embarrassment/shame of being diagnosed with breast cancer } \\
\hline Yes & $1.75(0.97,3.16)$ & $1.13(0.55,2.35)$ & & \\
\hline No & Referent & Referent & & \\
\hline \multicolumn{5}{|c|}{ Do you often use the Internet for sources of information? } \\
\hline No & $1.33(1.05,1.70)^{*}$ & $0.94(0.76,1.17)$ & $1.07(0.79,1.46)$ & $1.02(0.78,1.34)$ \\
\hline Yes & Referent & Referent & Referent & Referent \\
\hline
\end{tabular}

Notes: $* P<0.05 ; * * P<0.01$. 
Table 3 Odds ratio and $95 \%$ confidence intervals from the multinomial analysis of enabling factor in relation to mammography screening status

\begin{tabular}{|c|c|c|c|c|}
\hline & \multicolumn{2}{|c|}{ Univariate multinomial model } & \multicolumn{2}{|c|}{ Multivariate multinomial model } \\
\hline & $\begin{array}{l}\text { Never screened vs } \\
\text { compliance }\end{array}$ & $\begin{array}{l}\text { Non-compliance vs } \\
\text { compliance }\end{array}$ & $\begin{array}{l}\text { Never screened vs } \\
\text { compliance }\end{array}$ & $\begin{array}{l}\text { Non-compliance vs } \\
\text { compliance }\end{array}$ \\
\hline \multicolumn{5}{|c|}{ Have a regular physician to visit } \\
\hline No & $6.79(4.37,10.55)^{* *}$ & $3.43(2.26,5.21)^{* *}$ & $2.74(1.26,5.97)^{*}$ & $2.39(1.15,4.95)^{*}$ \\
\hline Yes & Referent & Referent & Referent & Referent \\
\hline \multicolumn{5}{|c|}{ Importance of being screened for cancers } \\
\hline Not important & $\mathrm{I} .72(1.07,2.77)^{*}$ & $1.58(1.01,2.48)^{*}$ & $1.07(0.56,2.05)^{*}$ & $1.13(0.64,1.99)$ \\
\hline Somewhat important & $3.01(1.79,5.06)^{* *}$ & $1.59(0.95,2.66)$ & $2.41(1.05,5.55)^{*}$ & $0.70(0.31,1.61)$ \\
\hline Very important & Referent & Referent & Referent & Referent \\
\hline \multicolumn{5}{|c|}{ Insurance covers breast cancer screenings } \\
\hline No & $6.54(3.67,11.66)^{* *}$ & $6.56(3.67, \mathrm{I} 1.70)^{* *}$ & $4.65(2.23,9.67)^{* *}$ & $4.86(2.55,9.25)^{* *}$ \\
\hline Yes & Referent & Referent & Referent & Referent \\
\hline \multicolumn{5}{|l|}{ Communication problem } \\
\hline Yes & $2.33(1.53,3.54)^{* *}$ & $1.82(1.21,2.76)^{* *}$ & I.0I $(0.50,2.04)$ & $0.78(0.42,1.46)$ \\
\hline No & Referent & Referent & Referent & Referent \\
\hline \multicolumn{5}{|c|}{ Transportation to the facility } \\
\hline No & $3.02(1.97,4.66)^{* *}$ & $2.68(1.75,4.10)^{* *}$ & $1.29(0.57,2.92)$ & $2.32(1.07,5.05)^{*}$ \\
\hline Yes & Referent & Referent & Referent & Referent \\
\hline \multicolumn{5}{|l|}{ Lack of knowledge } \\
\hline Yes & $2.34(1.57,3.50)^{* *}$ & $1.42(0.96,2.09)$ & $0.88(0.44,1.75)$ & $0.86(0.47,1.59)$ \\
\hline No & Referent & Referent & Referent & Referent \\
\hline \multicolumn{5}{|c|}{ Know where to get services } \\
\hline No & $4.29(2.74,6.73)^{* *}$ & $2.18(I .43,3.31)^{* *}$ & $2.59(1.12,6.02)^{*}$ & $\mathrm{I} .15(0.53,2.5 \mathrm{I})$ \\
\hline Yes & Referent & Referent & Referent & Referent \\
\hline
\end{tabular}

Notes: $* P<0.05 ; * * p<0.01$.

Koreans and Vietnamese counted for a similar percentage of compliance with $15.74 \%$ and $14.87 \%$, respectively.

\section{Cultural factors}

Of the seven cultural variables analyzed individually in relation to the screening status adjusting for the ethnicity variable, five variables significantly differentiated between the never-screened and the screened. Those who lived in the United States for less than 15 years were more likely to be never-screened than those who had lived in the United States for 15 or more years $(\mathrm{OR}=1.67,95 \%, \mathrm{CI}=1.36,2.04)$. Those who did not speak English at all were more likely

Table 4 Odds ratio and $95 \%$ confidence intervals from the multinomial analysis of environmental factor in relation to mammography screening status

\begin{tabular}{|c|c|c|c|c|}
\hline & \multicolumn{2}{|c|}{ Univariate multinomial model } & \multicolumn{2}{|c|}{ Multivariate multinomial model } \\
\hline & $\begin{array}{l}\text { Never screened vs } \\
\text { compliance }\end{array}$ & $\begin{array}{l}\text { Non-compliance vs } \\
\text { compliance }\end{array}$ & $\begin{array}{l}\text { Never screened vs } \\
\text { compliance }\end{array}$ & $\begin{array}{l}\text { Non-compliance vs } \\
\text { compliance }\end{array}$ \\
\hline \multicolumn{5}{|c|}{ Making appointments for medical care } \\
\hline Poor/fair & $1.76(1.15,2.67)^{*}$ & I.3I $(0.87,1.99)$ & I.34 $(0.74,2.40)$ & I.45 $(0.83,2.54)$ \\
\hline Good/excellent & Referent & Referent & Referent & Referent \\
\hline \multicolumn{5}{|c|}{ Waiting time to see the doctor } \\
\hline Poor/fair & I.09 (0.7I, I.69) & $0.93(0.6 \mathrm{I}, \mathrm{I} .42)$ & & \\
\hline Good/excellent & Referent & Referent & & \\
\hline \multicolumn{5}{|c|}{ Time between making an appointment for care and the day of your visit } \\
\hline Poor/fair & $1.53(0.98,2.38)$ & $1.12(0.73,1.73)$ & & \\
\hline Good/excellent & Referent & Referent & & \\
\hline \multicolumn{5}{|c|}{ Rating of the care of medical group } \\
\hline Poor/fair & $1.98(1.28,3.08)^{* *}$ & I.I2 $(0.74,1.70)$ & $1.50(0.84,2.68)$ & $0.83(0.47,1.44)$ \\
\hline Good/excellent & Referent & Referent & Referent & Referent \\
\hline
\end{tabular}

Notes: $* P<0.05 ; * * P<0.0$ I. 
Table 5 Odds ratio and $95 \%$ confidence intervals from the multinomial analysis of family and social support factor in relation to mammography screening status

\begin{tabular}{|c|c|c|c|c|}
\hline & \multicolumn{2}{|c|}{ Univariate multinomial model } & \multicolumn{2}{|c|}{ Multivariate multinomial model } \\
\hline & $\begin{array}{l}\text { Never screened vs } \\
\text { compliance }\end{array}$ & $\begin{array}{l}\text { Non-compliance vs } \\
\text { compliance }\end{array}$ & $\begin{array}{l}\text { Never screened vs } \\
\text { compliance }\end{array}$ & $\begin{array}{l}\text { Non-compliance vs } \\
\text { compliance }\end{array}$ \\
\hline \multicolumn{5}{|c|}{ Discussed breast cancer with your significant other or family } \\
\hline No & $1.07(0.63,1.85)$ & $0.82(0.48,1.43)$ & & \\
\hline Yes & Referent & Referent & & \\
\hline \multicolumn{5}{|c|}{ Family/friend had a mammogram } \\
\hline No & $17.4(9.33,32.3)^{* *}$ & $3.03(1.85,4.95)^{* *}$ & $17.4(9.33,32.3)^{* *}$ & $3.03(1.85,4.95)^{* *}$ \\
\hline Yes & Referent & Referent & Referent & Referent \\
\hline
\end{tabular}

Notes: $* P<0.05$; $* * P<0.01$. The family/friend had the mammogram became the only significant variable. Therefore, the results are the same regardless if we run the multivariate or not.

to be never-screened than those who spoke English well $(\mathrm{OR}=1.96,95 \%, \mathrm{CI}=1.44,2.66)$. Those who disagreed with the belief that cancer is curable were more likely to be never-screened $(\mathrm{OR}=1.29,95 \%, \mathrm{CI}=1.03,1.62)$. Those who feared getting a bad test results were more likely to be neverscreened $(\mathrm{OR}=1.54,95 \%, \mathrm{CI}=1.07,2.21)$. Those not using the Internet for sources of information were more likely to be never-screened $(\mathrm{OR}=1.33,95 \%, \mathrm{CI}=1.05,1.70)$. However, none of these variables significantly differentiated between the non-compliance and the compliance (Table 2).

When including the above five significant variables from the univariate analysis into the multivariate multinomial model, two variables remained significant. Those who lived in the United States for less than 15 years were more likely to be never-screened than those living in the United States for 15 years or more $(\mathrm{OR}=1.65,95 \%, \mathrm{CI}=1.29,2.12)$. Those who did not speak English at all were more likely to be never-screened than those who spoke English well $(\mathrm{OR}=1.67,95 \%, \mathrm{CI}=1.20,2.52)$. None of these variables significantly differentiate between the non-compliance and the compliance in the multivariate multinomial model.

\section{Enabling factors}

When enabling variables were analyzed individually in relation to the screening status adjusting for the ethnicity variable, all seven variables significantly differentiated between the neverscreened and the compliance. Those without a regular physician to visit were more likely to be never-screened than those with a regular physician to visit $(\mathrm{OR}=6.79,95 \%, \mathrm{CI}=4.37,10.55)$. Those who did not perceive the importance of being screened for cancers and those who said they thought the screening was somewhat important were more likely to be never-screened compared with those who believed the screening was very important $(\mathrm{OR}=1.72,95 \%, \mathrm{CI}=1.07,2.77 ; \mathrm{OR}=3.01,95 \%$, $\mathrm{CI}=1.79,5.06$, respectively). Those who did not have health insurance to cover the breast cancer screening cost were more likely to be never-screened $(\mathrm{OR}=6.54,95 \%, \mathrm{CI}=3.67,11.66)$. Those who had no transportation to the facility were more likely to be never-screened than those who did not $(\mathrm{OR}=3.02,95 \%$, $\mathrm{CI}=1.97,4.66)$. Those who indicated having communication problems were more likely to be never-screened $(\mathrm{OR}=2.33$, $95 \%, \mathrm{CI}=1.53,3.54)$. Those who lacked knowledge were more likely to be never-screened $(\mathrm{OR}=2.34,95 \%, \mathrm{CI}=1.57,3.50)$. Those who did not know where to get services were more likely to be never-screened $(\mathrm{OR}=4.29,95 \%, \mathrm{CI}=2.74,6.73)$.

When non-compliance was compared with compliance, those without a regular physician $(\mathrm{OR}=3.43,95 \%, \mathrm{CI}=2.26$, 5.21), who did not perceive the importance of being screened for cancers $(\mathrm{OR}=1.58,95 \%, \mathrm{CI}=1.01,2.48)$, whose insurance did not cover the breast cancer screening cost $(\mathrm{OR}=6.56$, $95 \%, \mathrm{CI}=3.67,11.70)$, who had limited English proficiency $(\mathrm{OR}=1.82,95 \%, \mathrm{CI}=1.21,2.76)$, who had no transportation to the facility $(\mathrm{OR}=2.68,95 \%, \mathrm{CI}=1.75,4.10)$, and who did not know where to get services $(\mathrm{OR}=2.18,95 \%, \mathrm{CI}=1.43$, 3.31) were more likely to be non-compliant (Table 3 ).

When including the above seven significant variables from the univariate analysis into the multivariate multinomial model, four variables remained significant for the comparison between never-screened versus compliance: having a regular physician, perceiving the importance of being screened for cancers, having insurance that covered breast cancer screenings, and knowing where to get services. In comparison, three variables were significant for the comparison between the non-compliance and compliance: having a regular physician, having insurance that covers breast cancer screenings, and having transportation problems (to the facility).

\section{Environmental factors}

Of the four environmental variables analyzed individually in relation to the screening status adjusting for the ethnicity 
variable, two variables significantly differentiated between the never-screened and the screened. Those who reported that "arrangements for making appointments for medical care" were poor or fair were more likely to be never-screened $(\mathrm{OR}=1.76,95 \%, \mathrm{CI}=1.15,2.67)$. Those who rated the "care at their medical group" as poor or fair were more likely to be never-screened $(\mathrm{OR}=1.98,95 \%, \mathrm{CI}=1.28,3.08)$. However, none of these variables significantly predicted the non-compliance compared with the screened (Table 4). After including the above two significant variables from the univariate analysis into the multivariate multinomial model, none were significant.

\section{Family/social support factors}

One variable under the family and social support domain in relation to the screening status was significant. Those who did not report a family member or friend having a mammogram were more likely to be never-screened $(\mathrm{OR}=17.4,95 \%$ $\mathrm{CI}=9.33,32.3)$ and non-compliant $(\mathrm{OR}=3.03,95 \%$ $\mathrm{CI}=1.85,4.95)$. The multivariate multinomial model remained the same as only one variable was significant in the univariate analysis (Table 5).

\section{Discussion}

This study examined multiple levels of influence of demographic factors, enabling, cultural, environmental health system, and family/social support factors underlying breast cancer screening among Chinese, Korean, and Vietnamese American women using the Sociocultural Health Behavior Model. The study found some significant associations among the factors in the model.

Of the demographic variables, only ethnicity was related to breast screening status. Chinese were more compliant with screening status followed by Koreans and Vietnamese. Consistent with previous literature, ethnicity is a powerful predictor of the lack of breast cancer screening. ${ }^{29-31}$ Although marital status was often cited as a strong predictor for breast cancer screening, ${ }^{2,14}$ our results did not show this association. This may in part be due to the high proportion of married women among the participants in our study, which led to little variation.

Consistent with previous studies, ${ }^{14,18}$ acculturation factors seemed to have a great impact on breast cancer screening. This study found that there was an association between the lengths of time lived in the United States and the likelihood of screening. The longer a person had lived in the United States, the more likely they were to have ever been screened. Multivariate analysis also showed that among cul- tural variables, those who lived in the United States for less than 15 years and those who did not speak English were more likely to be never-screened than those living in the United States for longer than 15 years and who could speak English. In addition, our findings were in line with the literature that suggests cultural beliefs may play an important role in Asian American women's cancer screening behavior. ${ }^{32}$ Those who did not think cancer was curable, or who feared getting a bad test result, were less likely to have the screening.

Of the enabling factors, those who did not have a regular physician, did not have health insurance to cover the screening cost, did not recognize the importance of being screened for cancers, had language problems, lacked knowledge about breast cancer, or did not know where to get the services were more likely to have never been screened than those who did not have problems with these issues. With the exception of lack of knowledge and uncertainty about where to go for the services, all the other four factors were independently associated with screening behavior. These enabling factors also differentiated compliance from non-compliance for breast cancer screening. Without a regular physician and lack of health insurance to cover breast cancer screening, costs were the most significant barriers impeding Asian American women to access the screening. These findings corroborate the extant literature which suggests enabling factors, such as having health insurance and a usual source of care, are the strongest facilitators of receiving breast cancer screening. $8,14,33$

Of the environmental factors, those who reported that arrangements of appointments were poor or fair, and who rated the quality of care of the medical group as poor, were less likely to get screened for breast cancer than those who chose a good or excellent rating. Future studies are needed to confirm the independent impact of these factors.

Of the family/social factors, those who did not have family or friends getting a mammogram were less likely to get screened. Social support has been found to be effective in increasing breast cancer screening among other ethnic/ racial groups such as African Americans and appears to be so for Asian Americans as well. ${ }^{34}$ Having a family member or friend who had a mammogram increased the likelihood of being screened.

There were some limitations to the study. First, since the sample was drawn from Asian American women who participate in community organizations, the findings may not be generalizable to all Asian American women, especially those who do not participate in community-based organizations. Second, these findings are based on self-report questionnaires 
and as a result may include participant response bias and measurement error since some studies have found that the prevalence of cancer screening tests are often overestimated. ${ }^{35}$ Third, due to the nature of cross-sectional study, an association with breast cancer screening may not warrant a causal relationship.

Despite these limitations, using the Sociocultural Health Behavior Model, our study adds evidence to the growing body of literature with regard to the impact of sociocultural factors on Asian American womens' breast cancer screening behavior. The results of this study suggest that breast cancer screening programs will be more effective if they include the cultural and health beliefs, enabling, and social support factors associated with breast cancer screening. Sensitivity to ethnic and cultural factors, especially English language and other family or community contexts and dynamics, should be present throughout all secondary prevention activities, especially with the provision of culturally appropriate translation services and education materials in one's native language to enhance interventions which target improved breast screening rates among Asian Americans. Furthermore, the use of community organizations, which served as the basis for the study, can play a role in assisting Asian Americans in identifying, planning, and adopting effective evidence-based screening programs. Differences in services within an Asian ethnic population should be studied to determine the impact on breast cancer screening. The community organizations working in collaboration with representatives from local government, local health departments, culturally competent primary physicians, and other related partners, may be more successful than a single agency in implementing prevention and breast cancer screening programs.

\section{Acknowledgments}

The authors thank Asian Community Health Coalition partners, volunteers, community coordinators, and the research team at the Center for Asian Health, Temple University who facilitated and supported the completion of the study. This research was supported by National Institutes of Health, National Cancer Institute's Community Networks Program, grant U01 CA114582 ATECAR-Asian Community Cancer Network (PI: GXM) and grant U54 CA153513 Asian Community Cancer Health Disparities Center (PI: GXM).

\section{Disclosure}

The authors have no conflicts of interest to declare.

\section{References}

1. Jemal A, Siegel R, Ward E, Murray T, Xu J, Thun MJ. Cancer statistics, 2007. CA Cancer J Clin. 2007;57(1):43-66.

2. Kagawa-Singer M, Pourat N, Breen N, et al. Breast and cervical cancer screening rates of subgroups of Asian American women in California. Med Care Res Rev. 2007;64(6):706-730.

3. American Cancer Society. Cancer Facts and Figures 2010. Atlanta: American Cancer Society, 2010. Available from: http://www.cancer.org/ acs/groups/content/@nho/documents/document/acspc-024113.pdf.

4. Miller BA, Chu KC, Hankey BF, Ries LA. Cancer incidence and mortality patterns among specific Asian and Pacific Islander populations in the US. Cancer Causes Control. 2008;19(3):227-256.

5. Standford JL, Herrinton LJ, Schwartz SM, Weiss NS. Breast cancer incidence in Asian migrants to the United States and their descendants. Epidemiology. 1995;6(2):181-183.

6. Li FP, Pawlish K. Cancers in Asian Americans and Pacific Islanders: Migrant Studies. Asian Am Pac Isl J Health. 1998;6(2):123-129.

7. Su X, Ma GX, Seals B, Tan Y, Hausman A. Breast cancer early detection among Chinese women in the Philadelphia area. JWomens Health (Larchmt). 2006;15(5):507-519.

8. Ward E, Jemal A, Cokkinides V, et al. Cancer disparities by race/ethnicity and socioeconomic status. CA Cancer J Clin. 2004;54(2):78-93.

9. Hedeen AN, White E, Taylor V. Ethnicity and birthplace in relation to tumor size and stage in Asian American women with breast cancer. Am J Public Health. 1999;89(8):1248-1252.

10. Yu ES, Kim KK, Chen EH, Brintnall RA. Breast and cervical cancer screening among Chinese American women. Cancer Pract. 2001;9(2):81-91.

11. Yu MY, Hong OS, Seetoo AD. Uncovering factors contributing to under-utilization of breast cancer screening by Chinese and Korean women living in the United States. Ethn Dis. 2003;13(2):213-219.

12. National Cancer Institute. SEER Program Summary Report. 2007: $57-60$.

13. Ma GX, Shive SE, Wang MQ, Tan Y. Cancer screening behaviors and barriers in Asian Americans. Am J Health Behav. 2009;33(6): 650-660.

14. Lee HY, Ju E, Vang PD, Lundquist M. Breast and cervical cancer screening among Asian American women and Latinas: does race/ethnicity matter? J Womens Health (Larchmt). 2010;19(10):1877-1884.

15. Tu SP, Yasui Y, Kuniyuki AA, et al. Mammography screening among Chinese-American women. Cancer. 2003;97(5):1293-1302.

16. Centers for Disease Control and Prevention (CDC). Behavioral risk factor survey of Korean Americans - Alameda County, California, 1994. MMWR Morb Mort and Wkly Rep. 1997;46(33):774-777.

17. Lee EE, Fogg LF, Sadler GR. Factors of breast cancer screening among Korean immigrants in the United States. J Immigr Minor Health. 2006;8(3):223-233.

18. Islam N, Kwon SC, Senie R, Kathuria N. Breast and cervical cancer screening among South Asian women in New York City. J Immigr Minor Health. 2006;8(3):211-221.

19. Ho V, Yamal JM, Atkinson EN, Basen-Engquist K, Tortolero-Luna G, Follen M. Predictors of breast and cervical screening in Vietnamese women in Harris County, Houston, Texas. Cancer Nurs. 2005;28(2): 119-129.

20. Nguyen EV. Cancer in Asian American males: epidemiology, causes, prevention, and early detection. Asian Am Pac Isl J Health. 2003;10(2): 86-99. 
21. Lovejoy NC, Jenkins C, Wu T, Shankland S, Wilson C. Developing a breast cancer screening program for Chinese-American women. Oncol Nurs Forum. 1989;16(2):181-187.

22. Tang TS, Solomon LJ, McCracken LM. Cultural barriers to mammography, clinical breast exam, and breast self-exam among Chinese-American women 60 and older. Prev Med. 2000;31(5): 575-583.

23. Ma GX, Shive SE, Gao W, Tan Y, Wang MQ. Prostate cancer screening among Chinese American men: a structural model. Am J Health Behav. 2012;36(4):495-504.

24. Strecher VJ, Rosenstock IM. The health belief model. In: Glanz K LF, Rimer BK, Lewis FM, editors. Health Behavior and Health Education. Theory, Research, and Practice. San Francisco: Jossey-Bass; 2002:41-56.

25. Bandura A. Health promotion by social cognitive means. Health Educ Behav. 2004;31(2):143-164.

26. Baranowski T, Perry CL, Parcel GS. How individuals, environments, and health behavior interact: Social cognitive theory. In: Glanz K LF, Rimer BK, Lewis FM, editors. Health Behavior and Health Education: Theory, Research, and Practice. San Francisco: Jossey-Bass; 2002:165-184.

27. Andersen RM. Revisiting the behavioral model and access to medical care: does it matter? J Health Soc Behav. 1995;36(1):1-10.

28. http://www.census.gov [homepage on the Internet]. Washington DC: US Census Bureau. Profiles of General Demographic Characteristics. 2000 Census of Population and Housing. Issued May 2001. Available from: http://www.census.gov/prod/cen2000/dp1/2kh00.pdf. Accessed March 28, 2012.
29. Juon HS, Seo YJ, Kim MT. Breast and cervical cancer screening among Korean American elderly women. Eur J Oncol Nurs. 2002;6(4):228-235.

30. Juon HS, Choi Y, Kim MT. Cancer screening behaviors among KoreanAmerican women. Cancer Detect Prev. 2000;24(6):589-601.

31. Juon HS, Kim M, Shankar S, Han W. Predictors of adherence to screening mammography among Korean American women. Prev Med. 2004;39(3):474-481.

32. Wu TY, West B, Chen YW, Hergert C. Health beliefs and practices related to breast cancer screening in Filipino, Chinese and Asian-Indian women. Cancer Detect Prev. 2006;30(1):58-66.

33. Secginli S, Nahcivan NO. Factors associated with breast cancer screening behaviors in a sample of Turkish women: a questionnaire survey. Int J Nurs Stud. 2006;43(2):161-171.

34. Earp JA, Eng E, O’Malley MS, et al. Increasing use of mammography among older, rural African American women: results from a community trial. Am J Public Health. 2002;92(4):646-654.

35. Suarez L, Goldman DA, Weiss NS. Validity of Pap smear and mammogram self-reports in a low-income Hispanic population. Am J Prev Med. 1995;11(2):94-98.
International Journal of Women's Health

\section{Publish your work in this journal}

The International Journal of Women's Health is an international, peerreviewed open-access journal publishing original research, reports, reviews and commentaries on all aspects of women's healthcare including gynecology, obstetrics, and breast cancer. Subject areas include: Chronic conditions (migraine headaches, arthritis, osteoporosis);

\section{Dovepress}

Endocrine and autoimmune syndromes; Sexual and reproductive health; Psychological and psychosocial conditions. The manuscript management system is completely online and includes a very quick and fair peer-review system. Visit http://www.dovepress.com/ testimonials.php to read real quotes from published authors. 